\title{
Study disaster preparedness of libraries in Qazvin University of Medical Sciences, Iran (2017)
}

\author{
Sh. Zakiani ${ }^{1}, \underline{\text { S. Ghaffari }}^{2}$, Sh. Gholami ${ }^{3}$
}

\author{
${ }^{1}$ Faculty of Human Sciences, Payame Noor University, Mashhad, Iran \\ ${ }^{2}$ Library and Information Department, Payame Noor University, Qom, Iran \\ ${ }^{3}$ Department of Medical Information and Scientific Resource, Qazvin University of Medical Sciences, Qazvin, Iran \\ Corresponding Address: Saeed Ghaffari, Library and Information Department, Payame Noor University, Qom, Iran \\ Tel: +98-025-37179145; Email: ghaffari130@yahoo.com \\ Received: 9 Apr 2018; Accepted: 14 Aug 2018
}

\section{Abstract}

Background: Iran is an emergency state, and natural disaster such as; flood, earthquake or volcano may be occur any time. Therefore, libraries should be prepared for these incidents.

Objective: The purpose of this study was to assess the disaster preparedness of libraries in Qazvin University of Medical Sciences, Iran.

Methods: This applied research with analytical survey method was conducted in the libraries of Qazvin University of Medical Sciences, Iran in 2017. The study tool was a researcher-made questionnaire that included 5 sections and 57 questions in three dimensions; building, management and staff in evaluating the preparedness of the libraries against unexpected incidents. Validity of the questionnaire was confirmed by librarian and statistics and its reliability was 0.85 based on Cronbach's alpha coefficient.

Findings: Preparedness of the libraries of Qazvin University of Medical Sciences against flood, earthquake, fire, storm and thunder was 25\%,20\%,14\%,8\% and 5\%. The percentage of the libraries preparedness against all disasters were $14.4 \%$, indicating a poor librarian's readiness.

Conclusion: The results showed that university's readiness was weak in unexpected events and should provide a plan for natural disasters effectively.

Keywords: Disasters, Libraries, Earthquakes, Floods, Fires

Citation: Zakiani Sh, Ghaffari S, Gholami Sh. Study disaster preparedness of libraries in Qazvin University of Medical Sciences, Iran (2017). J Qazvin Univ Med Sci 2018; 22(4): 74-82. 


\title{
بررسى ميزان آمادتى كتابخانههاى دانشخًاه علوم يزشكى قزوين در مواجهه با بلاياى طبيعى
} (1)97)

\author{
شعله زكيانى'، دكتر سعيد غفارى '، شهرزاد غلامى '
}

' انشكده علوم انسانى دانشخاه ييام نور مشهل، مشهد، ايران

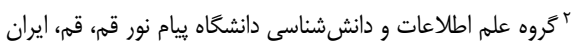

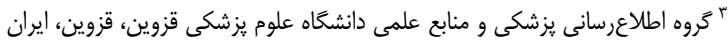

زمينه: ايران كشورى حادثهخيز است و هر زمان احتمال دارد حادثاى همجيون؛ سيل، زلزله و يا آتشفشان رخ دهد. بنابراين كتابخانهها بايد در برابـر اين حوادث آمادكى داشته باشند.

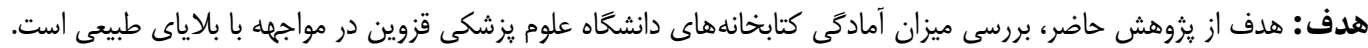

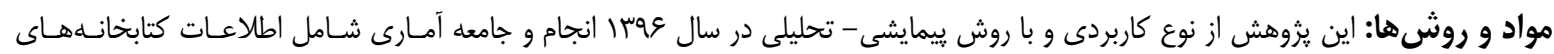

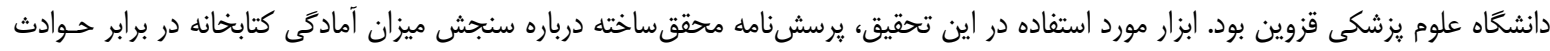

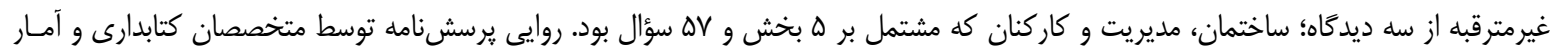

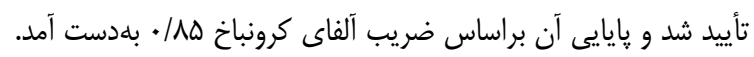

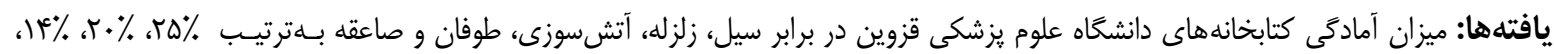

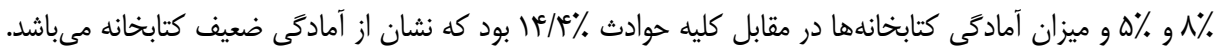

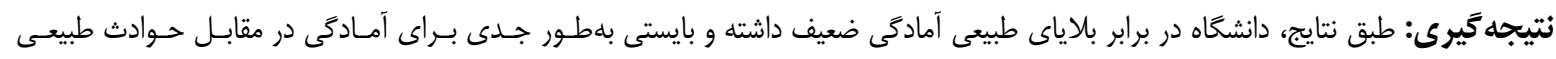
برنامهريزى كند.

كليدوازهها: بلاياى طبيعى، كتابخانهها، زلزله، سيل، آتشسوزى

مقدمه:

مى كند. اگرخه حوادث طبيعى غيرقابل ييش بينى هسـتند؛

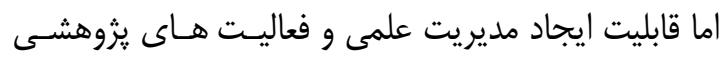

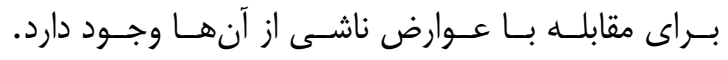

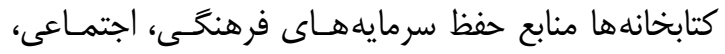

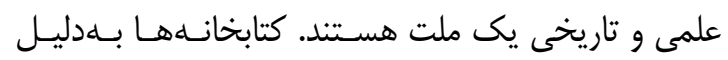

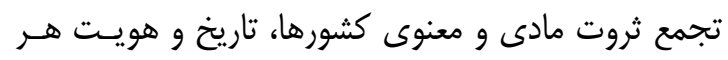

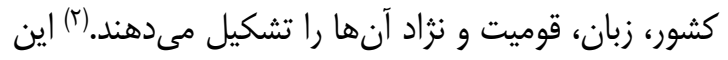
مكان ها بايد با انواع مختلف حوادث غيرطبيعى مقابله كنند

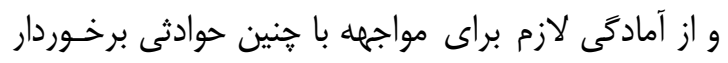

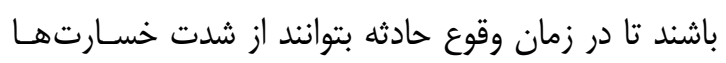

در ايران بلاياى طبيعى هر ساله خسارتهاى جـانى و وران

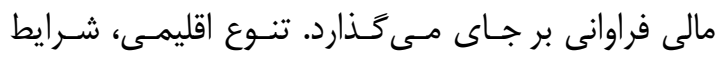

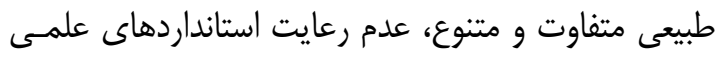

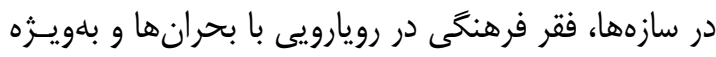

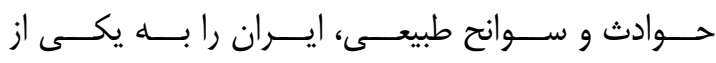

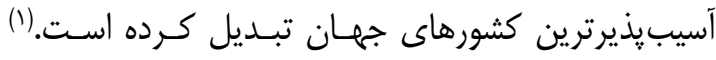

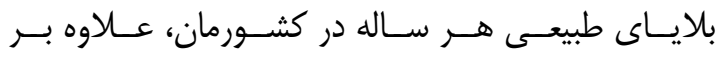

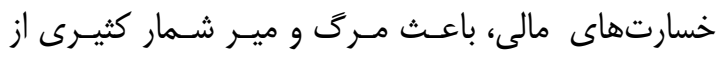

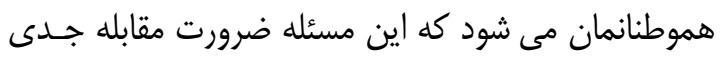

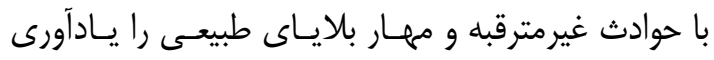


در سال 1994 و آتش سوزى كتابخانه ملى عراق در آوريل

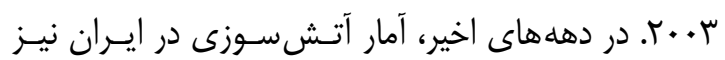

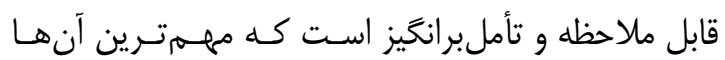

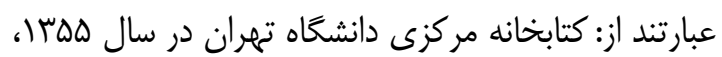

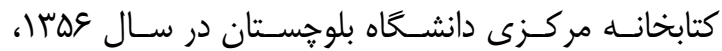

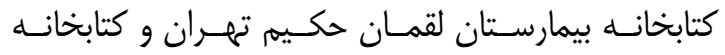

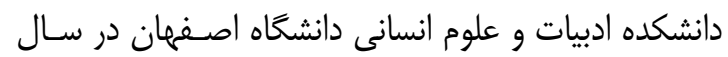
وعسا كه هم هزار جلد كتاب در آتش سـوخت. كتابخانسه دانشكده حقوق دانشگاه تهران در سال ^اسו تأسيس شد

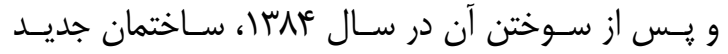

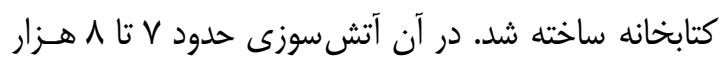
نسخه كتاب در آتش سوخت.

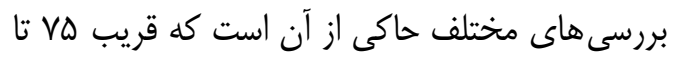

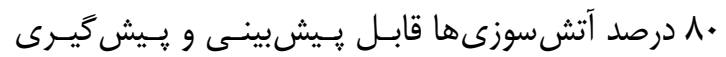

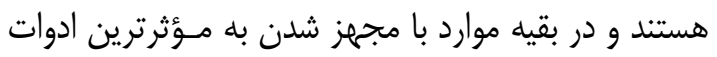

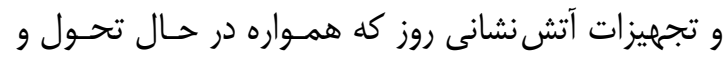
تكامل است مى توان ميزان خسارات را به حسداقل ممكـن

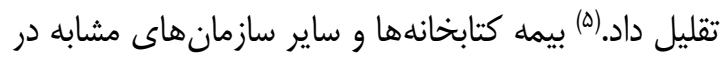
مقابل آتش سوزى لازم است ولى اخر تصـور شـود كـهـ بــا

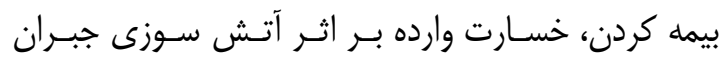

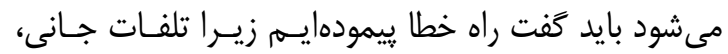

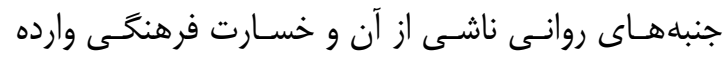
غيرقابل جبران است.

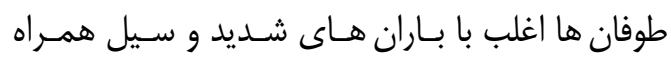
هستند.(9) كتابخانهها بهعنوان جزيى از بافـت اجتمـاعى و

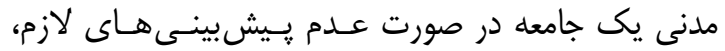

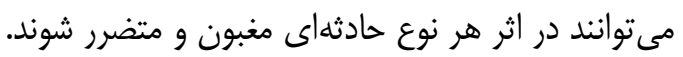

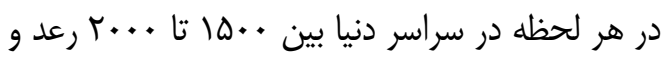

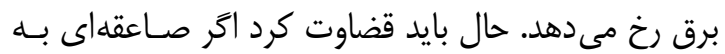

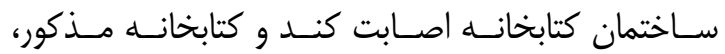

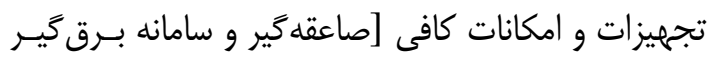

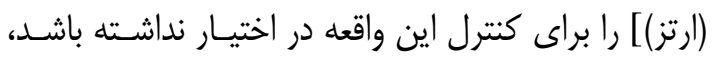
آن كاه مى توان صدمه و خسارت ناشى از آن را حسـدس زدان

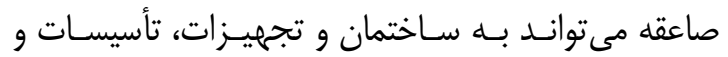

كم كنند. بديهى است قبل از هر حيز بايد حـوادث مـذكور

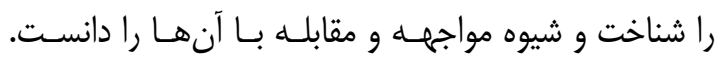

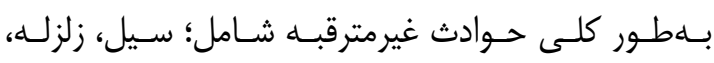
آتش سوزى، طوفان و صاعقه مىباشند. (")

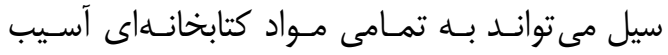

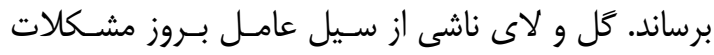

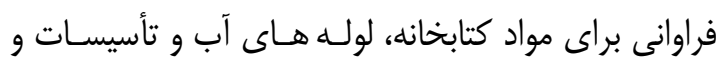

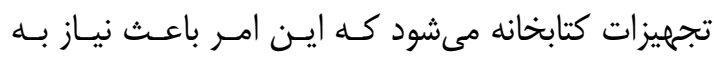

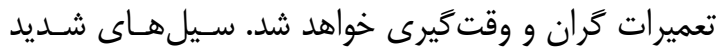

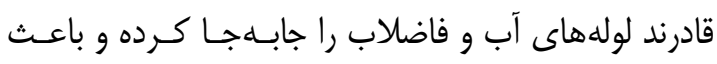

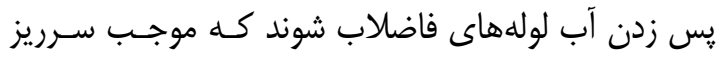

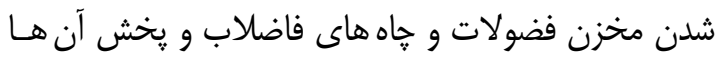

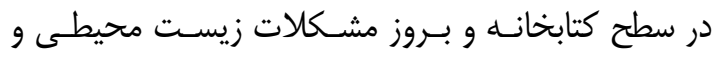

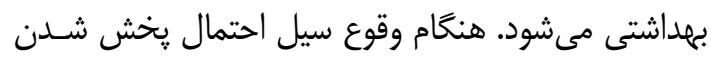

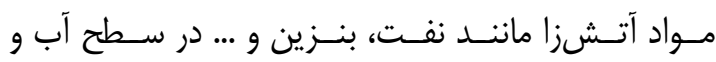

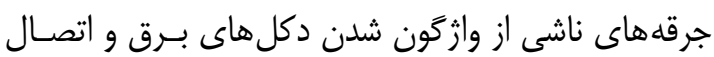

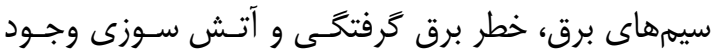
دارد.

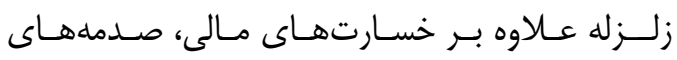

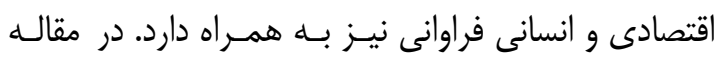

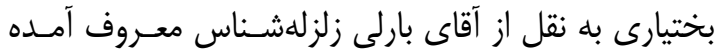

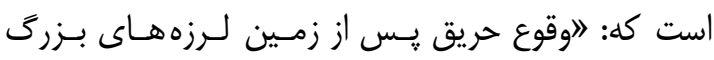

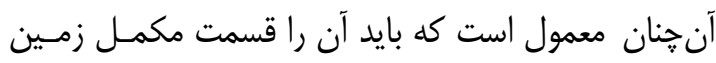

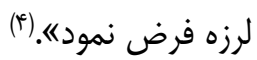

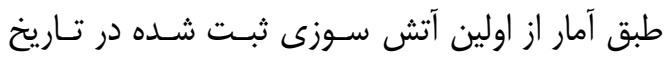

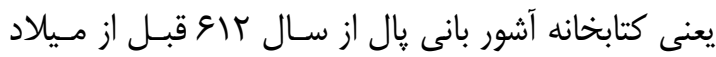

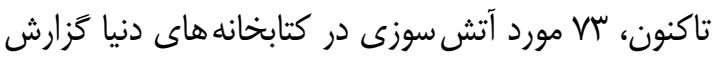

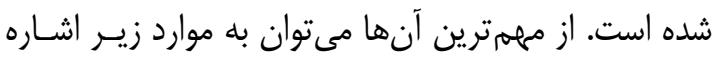

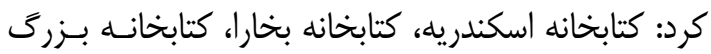

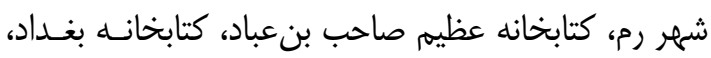

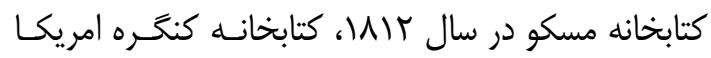

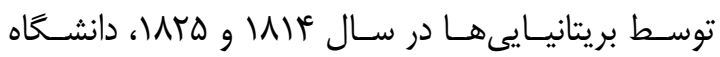

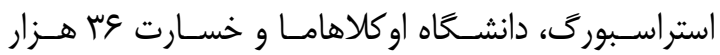
دلارى در سال ץ.91، كتابخانه مركزى نورويج انحلسـتان 
با معيارهاى ايمنى حريق نمسىباشـند.(9) تقـى جيـزرى و

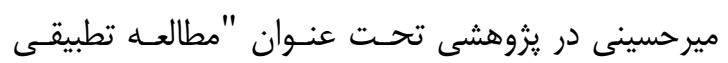

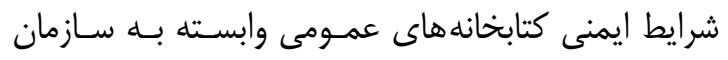

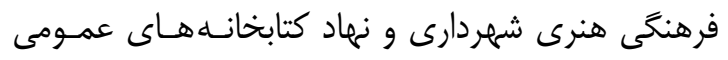
كشور در شهر قم" با بررسى شرايط ايمنى 9.1 كتابخانسه

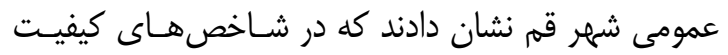

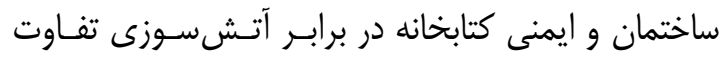

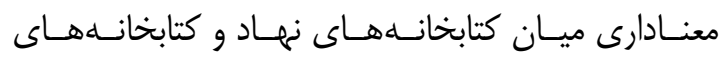

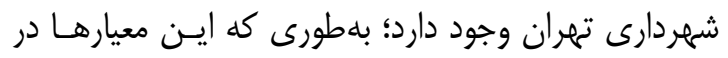
كتابخانه هاى عضو نهاد بيشتر رعايت شده بود. همجنين

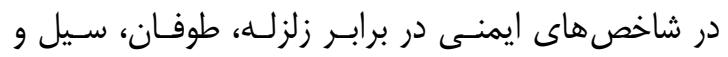
حفاظت در برابر عوامل بيولوزيكى تفاوت معنى دارى دئس بــين

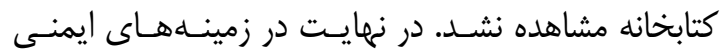

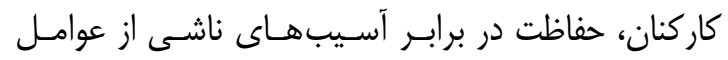

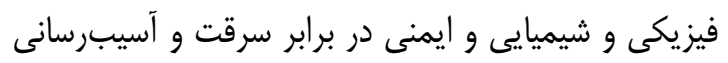

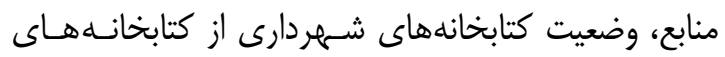
عضو نهاد بهتر ارزيابى شد. عنابع، وضعيت كتابخان نتايج مطالعه فرخى و بيات بداقى در بررسى وضـعيت ايمنى كتابخانههاى استان زنجان نشان داد كه در كل بين بين

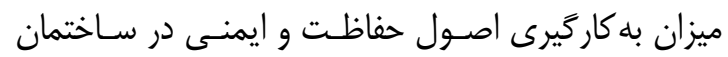

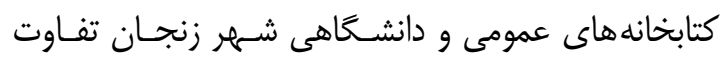

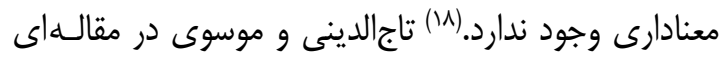

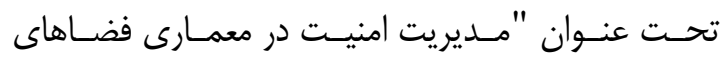

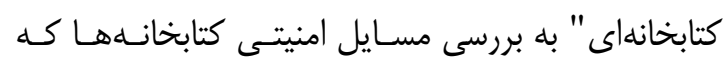
ارتباط نزديكى با نوع ساختمان، طراحى فضا، اداره سازمان

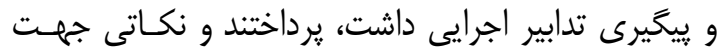
تنظيم و تدوين جارجوب ايمنسى كتابخانـهـهـا و اطلاعـات تجربى و عملى جهت مديريت امنيـت كتابخانـهـــا ارايـه كردند. (19) ملك الكلامى در ارزشيابى وضعيت عملكرد مـديريت

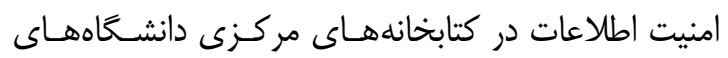

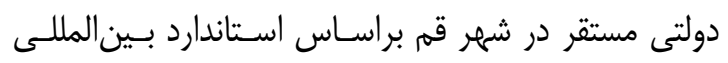

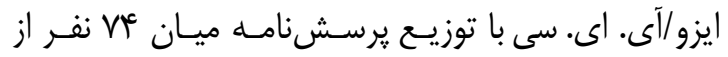

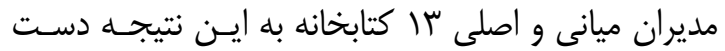

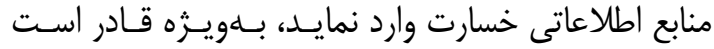
سامانه برق و رايانه كتابخانه را مختل و با مشكلات جدى إنى

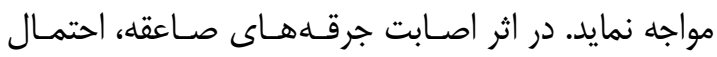
وقوع آتش سوزى و انفجار نيز وجود دارد. لذا كتابخانه بايد إندان

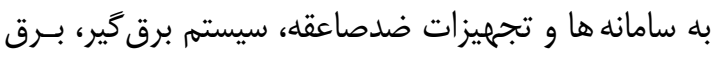

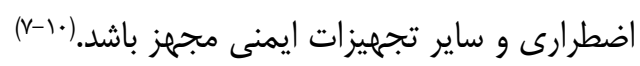

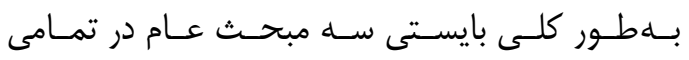

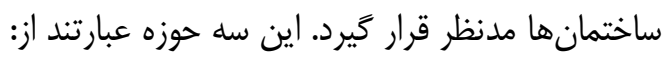

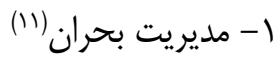
r- r (r) r- امنيت (r) نتايج يزوهش نيكنام تحت عنوان "بر رسى وضـعيت

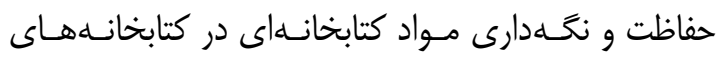

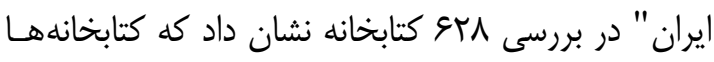

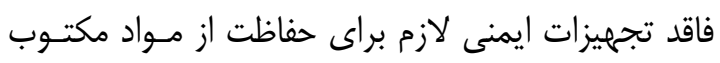

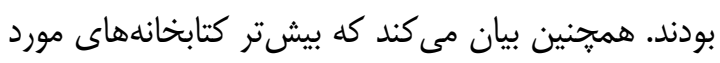

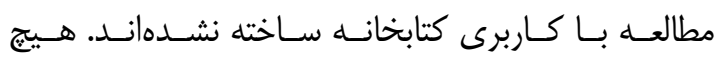

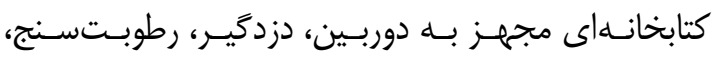

دماسنج و سيستمهاى هشداردهنده آتشسوزى نبود.(if) شعبانى در يزوهشى رعايت اصول ايمنى در ساختمان

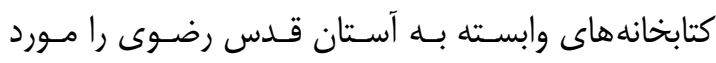

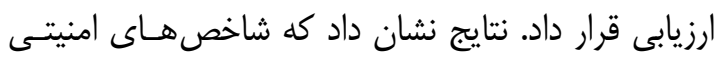

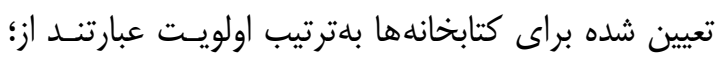
ايمنى در برابر خسارت ناشى از خرابى تأسيسات، ايمنى در

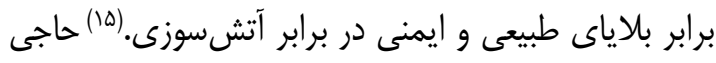

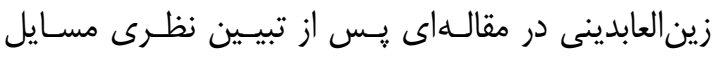

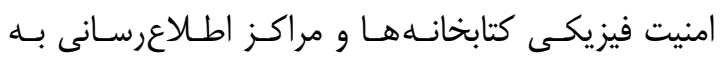

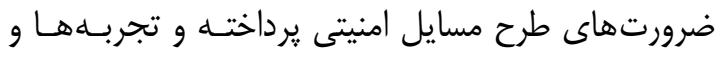

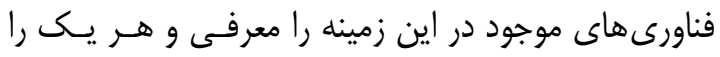

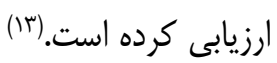
مير حسينى و ميراكبرى در بررسى وضـعيت ايمنسى در

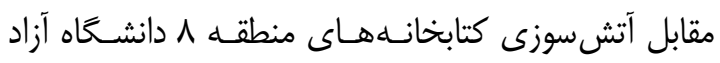

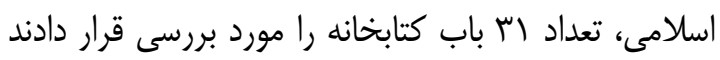

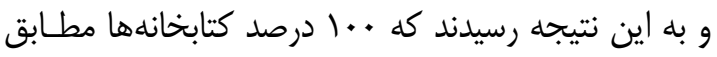


و در پايان راهكارهايى براى حل اين مشكلات ارايه شود.

\section{مواد و ورشها:}

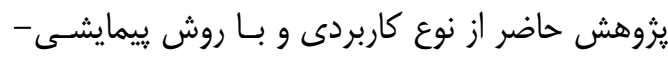
تحليلى در سال عوسا انجام شده است. جامعه آمارى ايـن

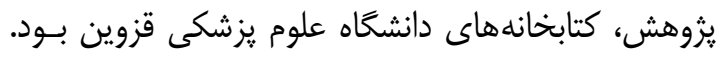

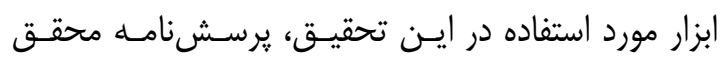

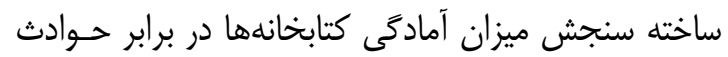
غيرمترقبه در يـنج مقولـه ايمنسى در برابـر سـيل، زلزيلها

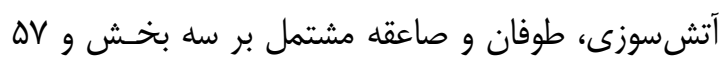

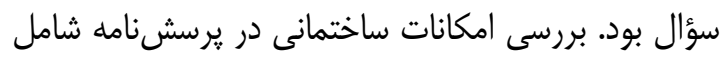

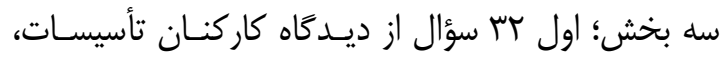

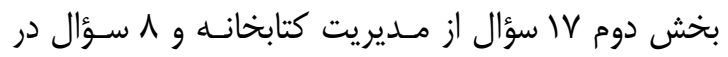

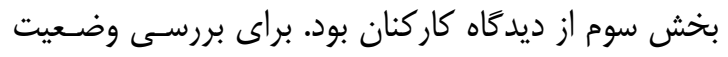

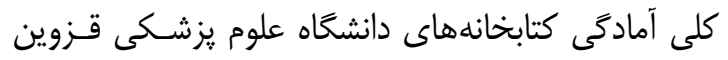

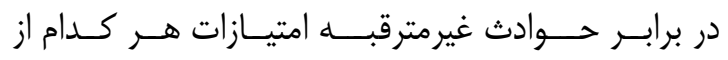
كتابخانهها در كل يعنى نمراتى كه هر كتابخانـه از تعـداد

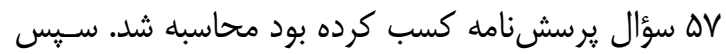

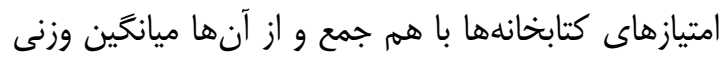

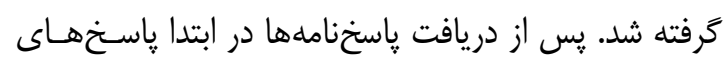

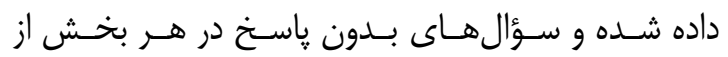

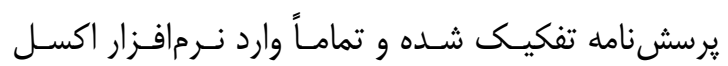

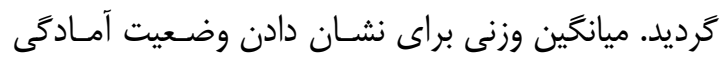

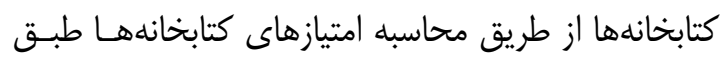

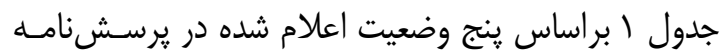

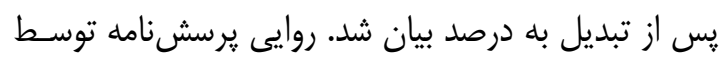
متخصصان كتابدارى و آمار دانشعاه علوم يزشـكى ايـــان

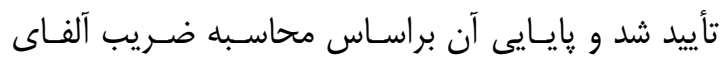

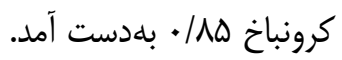

يرسش نامه ها از طريق مراجعه حضورى و مكاتبـه بـا

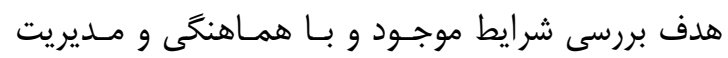

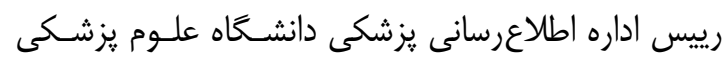
قزوين تكميل و ارسال شد. تجزيه و تحليل دادهها با استفاده از روش آمار توصيفى از طريق نرمافزار اكسل انجام شد.
يافت كـه در كتابخانسه مـورد هـروهش ميـانخين رعايـت

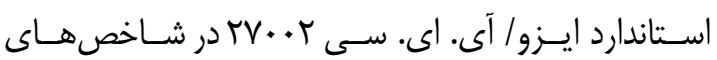

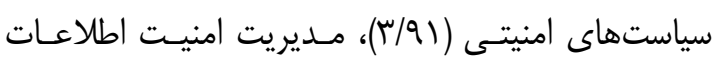

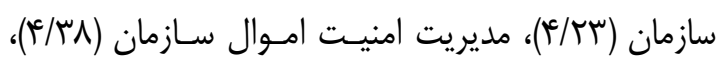

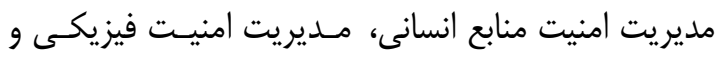

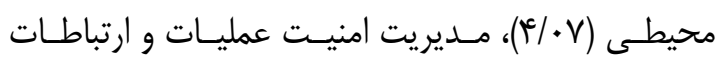

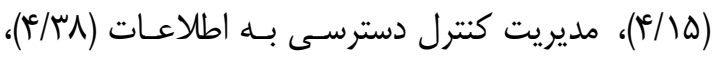

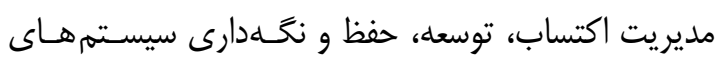

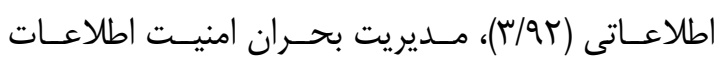

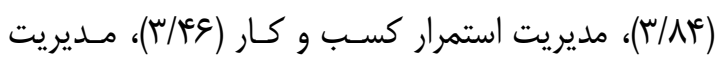

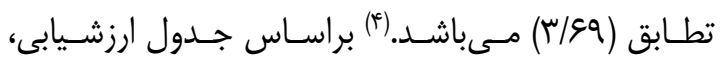

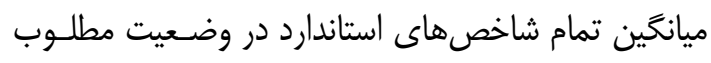

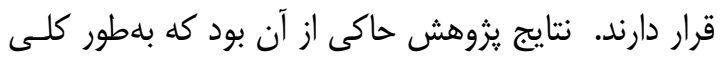

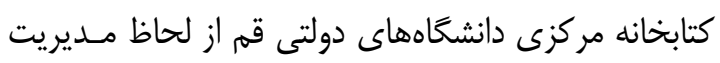
امنيت اطلاعات در شرايط مطلوبى قرار دارند و با اطمينان

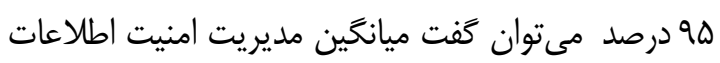

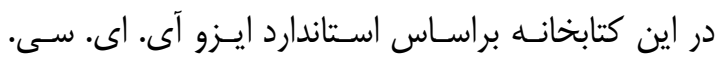

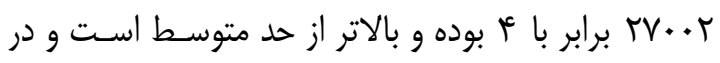

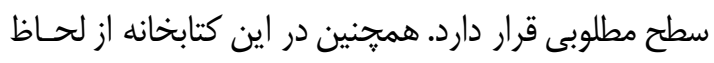

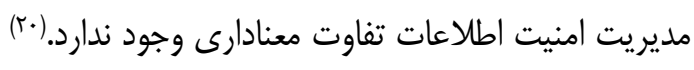

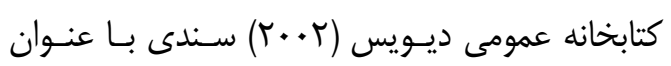

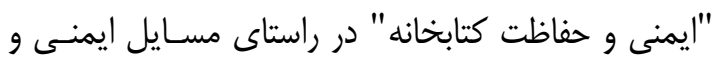

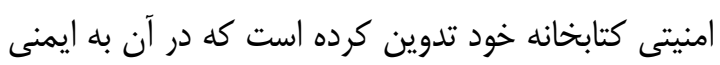

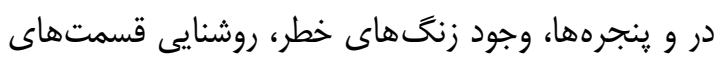

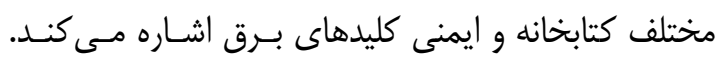

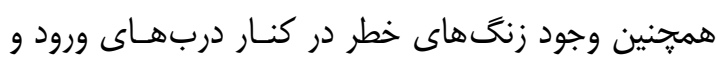
خروج را براى بالا رفتن ايمنى كتابخانه لازم مى داند.

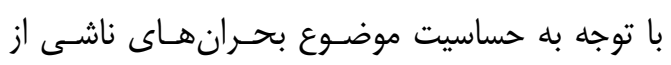

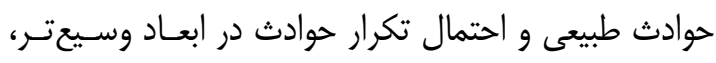

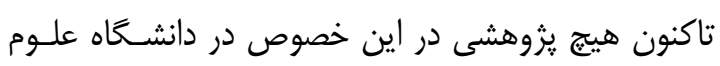
يزشكى قزوين انجام نشده است. لذا لازم دانستيم كه بـ بـهـ

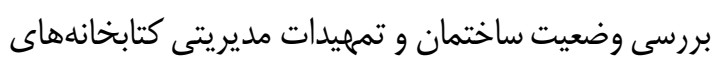

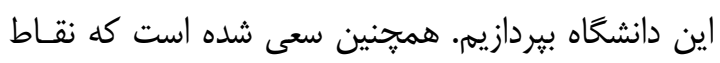

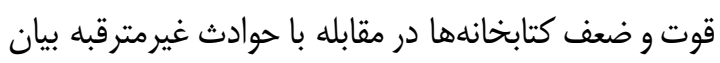


ميانكين نمرههاى كتابخانهاى مورد مطالعه براى طوفان

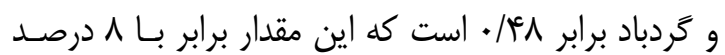

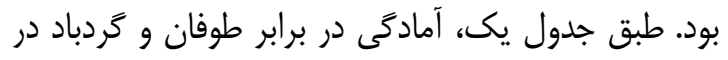

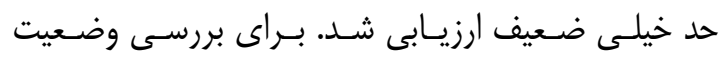

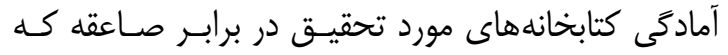

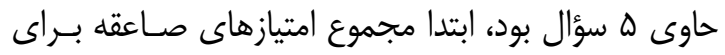

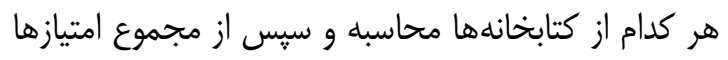

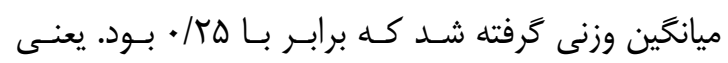

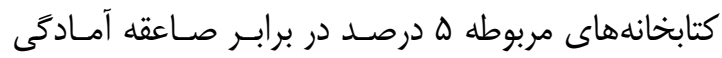

دارند كه در سطح بسيار ضعيف ارزيابى شد (نمودار ()).

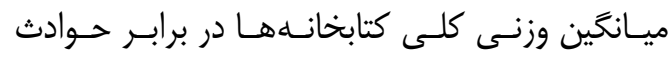

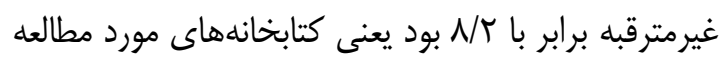

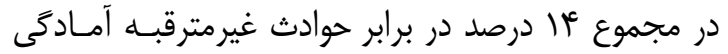
دارند كه براساس جدول يك وضعيت كلى كتابخانههــاى

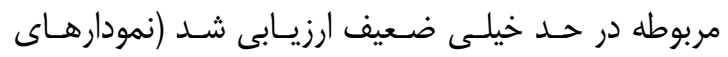

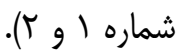

جدول ا - روش امتيازبندى يرسشنامه آمادكى كتابخانه در برابر حوادث غيرمترقبه

\begin{tabular}{|c|c|}
\hline وضعيت & امتياز كتابخانه \\
\hline عالى & $\wedge \cdot-1 . \cdot$ \\
\hline خوب & s. - - . \\
\hline متوسط & $f+-\varepsilon$. \\
\hline ضعيف & $r \cdot-r$. \\
\hline بسيار ضعيف & $\cdot-r$. \\
\hline
\end{tabular}

(1) يافتهها:

از ال السؤال در مـورد سـيل، بـهـ و سـؤال اول هـيجيج

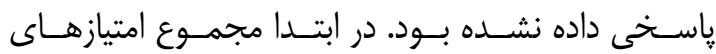

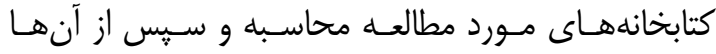
ميانگَين وزنى كَرفته شد. طبق نمـودار ا، ميـانخين وزنسى

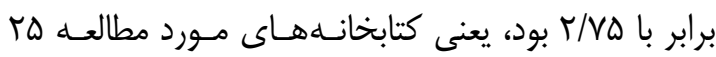

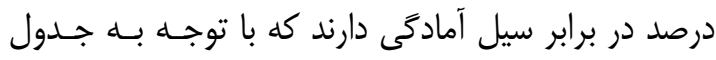

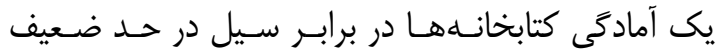

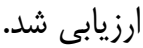

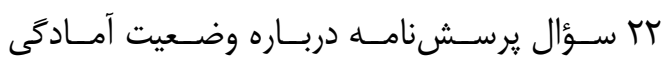

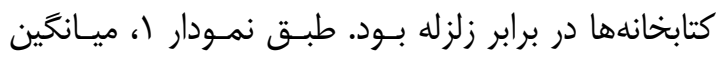

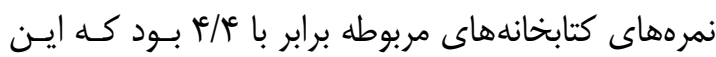

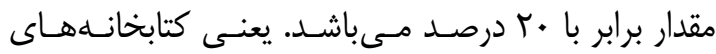

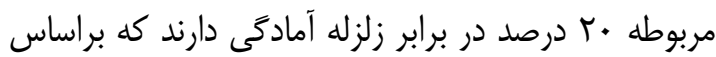

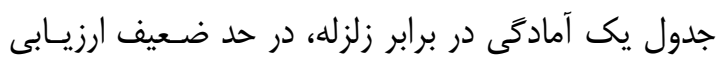

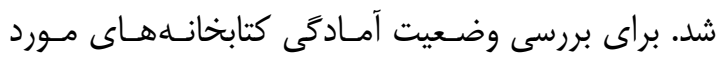

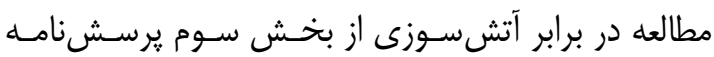

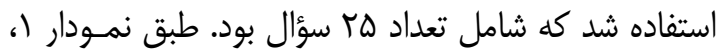

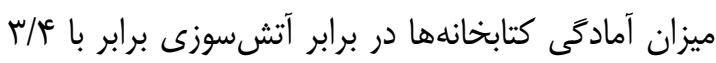

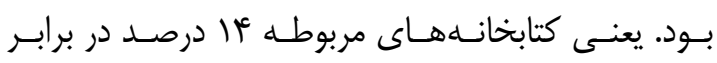

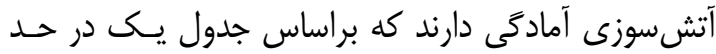
خيلى ضعيف ارزيابى شد.

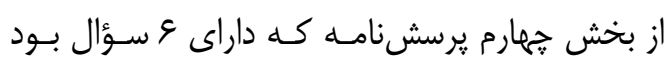

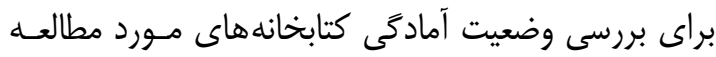

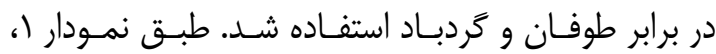

نمودار - ميانتَين آمادَّى كتابخانههاى دانشحاه علوم يزشكى قزوين در برابر حوادث طبيعى

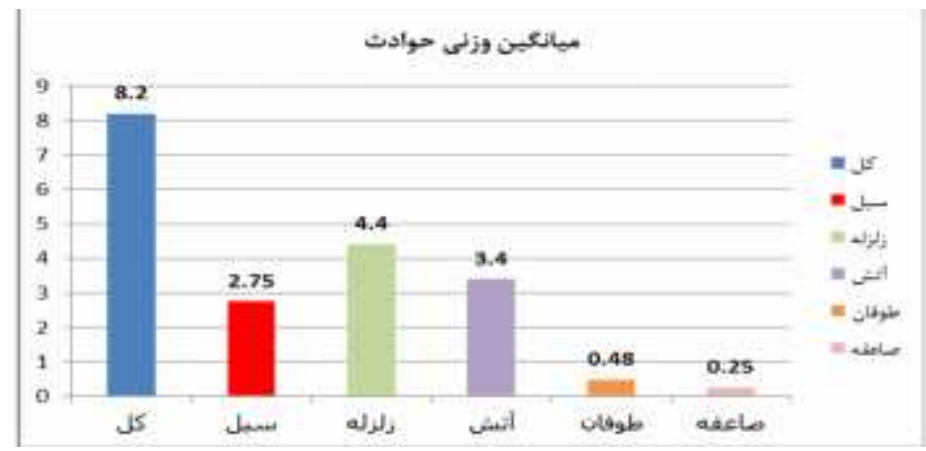




\section{نمودار r- درصد ميزان آمادكى كتابخانههاى مورد بررسى در برابر حوادث غيرمترقبه}

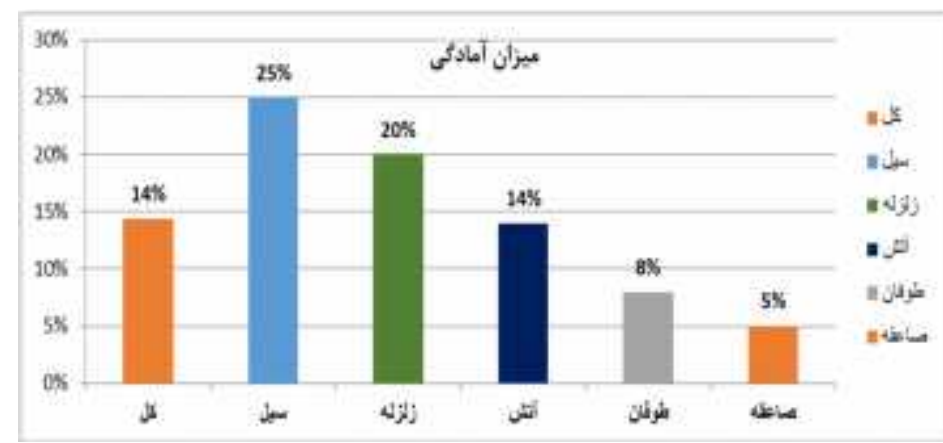

زمينه لازم است مديران ارشد كتابخانهها با سـازمانهـاى

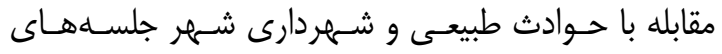

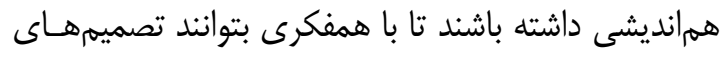

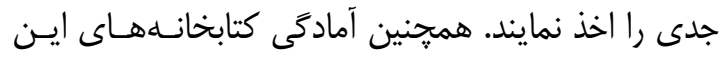

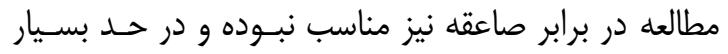

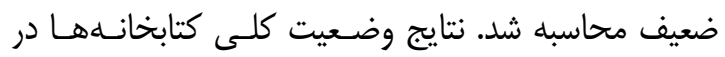

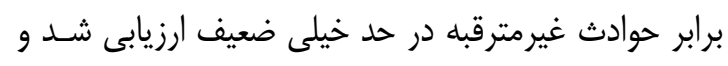

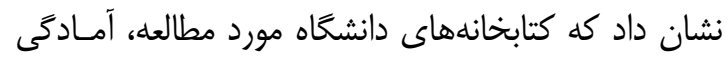
كافى در برابر حوادث غيرمترقبه را ندارد و نمى تواند امنيت

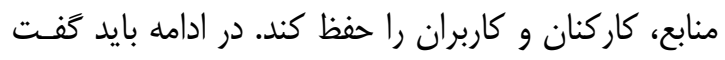

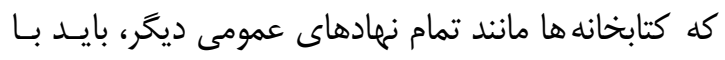

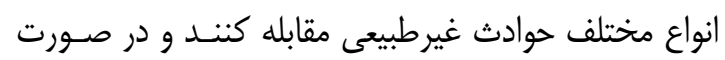

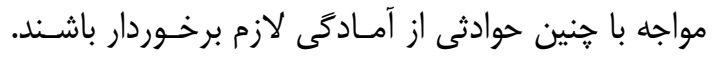

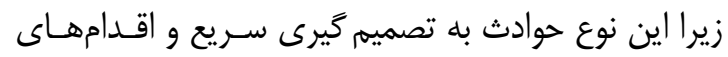
فورى نيازمند است. در اينجا، بنابر نتايج بهدست آمده از تحقيق يِيشنهاداتى

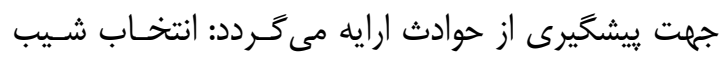

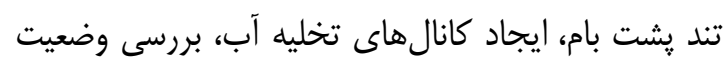

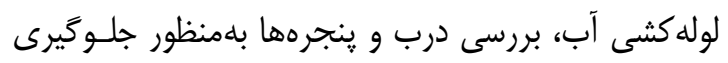

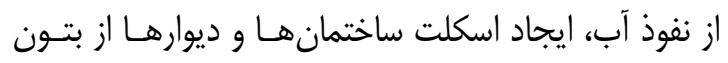

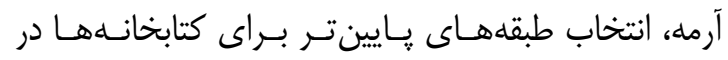

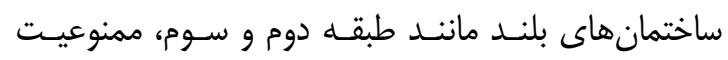

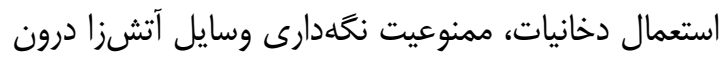
ساختمان كتابخانه، نغَهدارى صحيح از وسـايل كتابخانسه،

\section{بحث و نتيجه كيرى:}

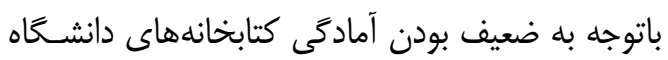

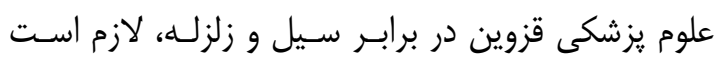

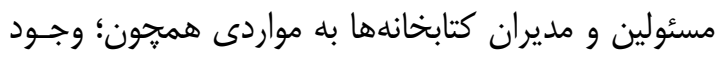

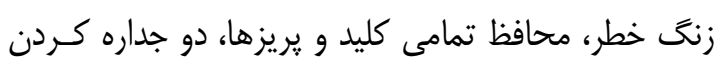

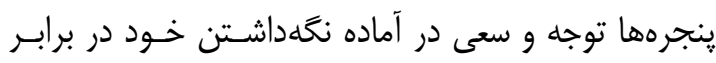

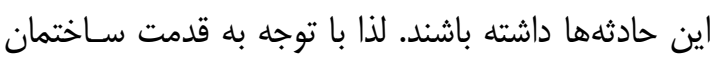

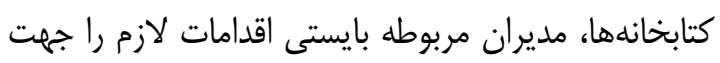

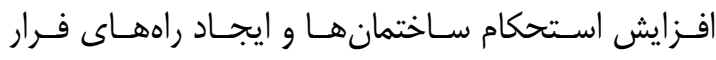

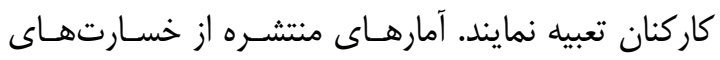

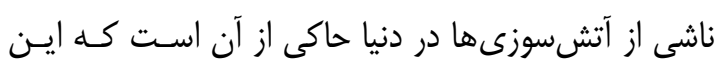

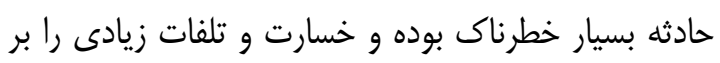

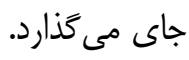

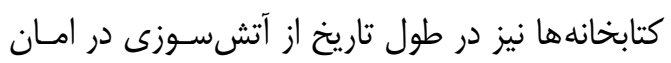

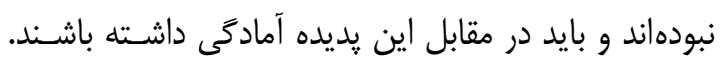

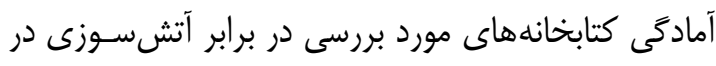

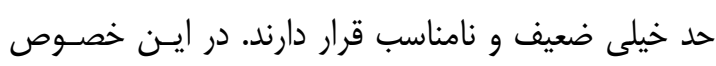

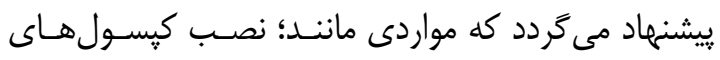

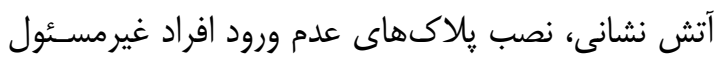

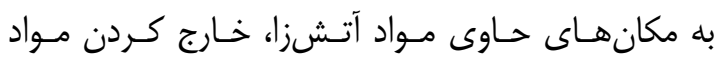

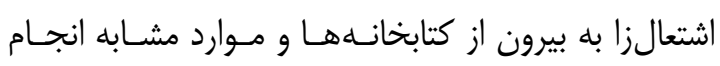

آمادَى كتابخانهها در برابـر طوفـان و كردبـاد خيلى

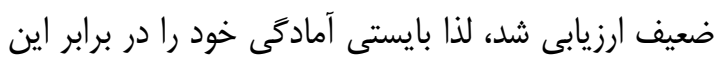

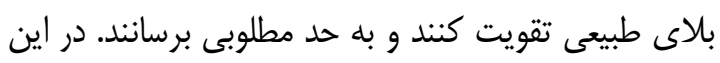


4. Bakhtyari S. Investigation of earthquakerelated fires in the world. Farhange eimeni; 2002; 1(2): 54. [In Persian]

5. Ministry of Health and Medical Education: Available at: http://www.behdasht.gov.ir/ $? \% 20$ siteid $=326 \&$ pageid $=32629 \&$ newsview $=$ 111528

6. Mahallati M. Library protection from fire hazards. Ayeneye Pazhoohesh 1998; 8(44): 2-

6. [In Persian]

7. Marjani A. Identification and introduction of the major natural and abnormal causes of damage to libraries: recommendations and strategies. Electronic J Library, Museums and Documents Center of Astan Quds Razavi 2014; 5(18): 1-20. [In Persian]

8. Asl Hashemi A. Emergency health measures. Tehran: Akhtar; 2006. 47-85. [In Persian]

9. Ismail Zadeh A. Extreme natural hazards, disaster risks and societal implications. 1st ed. New York: Cambridge University Press; 2014. 402.

10. Zolala F. Data collection after massive natural disasters (focusing on Bam earthquake, Iran). Disaster Prev Manag 2010; 19(5): 541-7. doi: 10.1108/ 09653561011091878.

11. Farazmand A. Learning from Katrina crisis: a global and international perspective with implications for future crisis management. Public Administration Review 2007; 67(S1): 149-59. doi: 10.1111/j.15406210.2007.00824.x.

12. Joukar T. Fundamentals and principles of security management in libraries. National studies on librarianship and information organization 2004; 15(3): 51-62. [In Persian]

13. Hajizeinolabedini M. Security issues and issues in libraries and information centers: an examination of humanitarian aspects. Mah

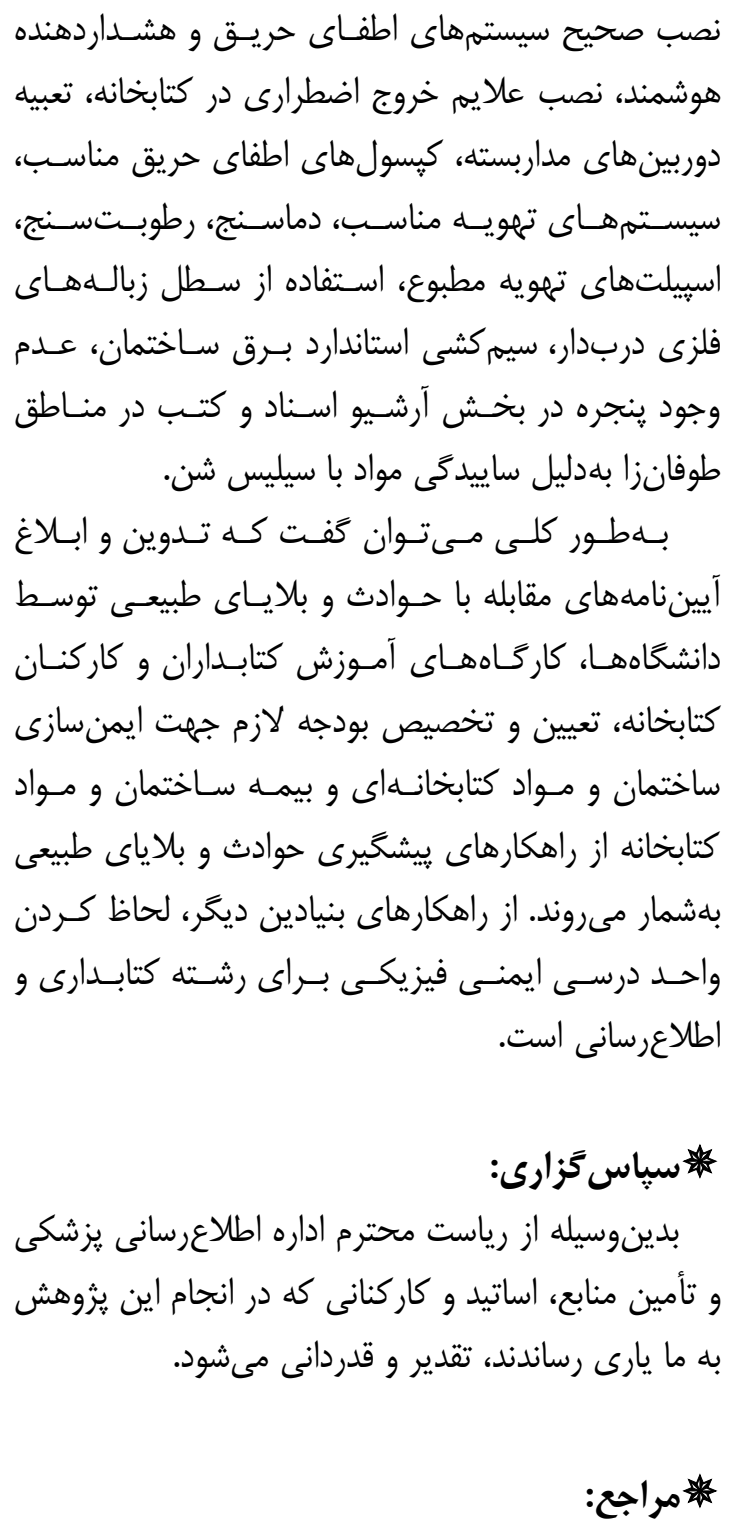

1. Marjani A. Identification and introduction of the major natural and abnormal causes of damage to libraries: recommendations and strategies. Electonical J Astan Guds 2013: 5(18): 1-20. [In Persian]

2. Niknam M. Firefighting. Tehran: Islamic Republic of Iran Documents and Library; 2006. [In Persian]

3. Niknam M. Study of the preservation and maintenance of library materials in Iranian libraries. National studies on librarianship and information 2003; 52: 30-53. [In Persian] 
koliat book: 2009; 124(11): 16-25. [In Persian]

14. Niknam M. National planning to preserve libraries' resources when natural disasters occur. 1st International Conference on Natural Disasters in Urban Areas, Part III: Crisis Management. 1993; Tehran; quality management CO: 85-92. [In Persian]

15. Sha'bani A, Marjani A. The managers' opinion on the safety and health of the libraries administered by the Astan Qods Razavi's center of documents. Health Inform Manage 2007; 4(2): 223-30. [In Persian]

16. Mirhoseini Z, Mirakbari M. Investigation of fire safety in the libraries of the 8th Islamic Azad University of libraries. Res Inform Sci Public Libraries 2010; 2(4): 59-70. [In Persian]

17. Mirhoseini Z, Taghi Chizari M. Comparative study of safety conditions in the public libraries of municipality organization for culture \& arts of Iran public libraries foundation in Tehran. Res Inform Sci Public Libraries 2011; 16(4): 151-82. [In Persian]
18. Farokhi F, Bayat Badaghi N. Assessment of Physical Security and Safety Conditions in Public and Academic Libraries: the Case of Zanjan Province. National Studies Librarianships Inform Organization (NASTINFO) 2011; 21(4): 22-33. [In Persian]

19. Tajedini O, Musavi A. Security management in library architecture. Moon Book 2011; 149: 64-67. [In Persian]

20. Malekolkalami M. Evaluation of the central libraries information security management at governmental universities located in Tehran, according to the international standard ISO/IEC 27002. Iran J Inform Processing Manage 2014; 28(4): 895916. [In Persian]

21. UC Davis General Library: Administrative Unit Review. Library safety and security 2002. Available at: http://library.ucdavis.edu.pd. 